Sonic Scope: New Approaches to Audiovisual Culture

\title{
Musical Videos as Works: Documenting Audiovisual Jazz Practices in Social Media Communities
}

Chris J. Cottell

Published on: Feb 15, 2021

DOI: 10.21428/66f840a4.53ae3b48

License: Creative Commons Attribution 4.0 International License (CC-BY 4.0). 


\section{ABSTRACT}

Musical Videos as Works: Documenting Audiovisual Jazz Practices in Social Media Communities Chris J. Cottell, Goldsmiths, University of London

Recent philosophical writing on jazz lacks attention to practices outside the instrumental, live, solo-based jazz ontology. Drawing on anthropological work theory, this study explores two examples of collaborative, social media-based jazz video practices: Jacob Collier's \#IHarmU fan-collaboration videos, and video transcription practices on the Facebook group "Jam of the Week." I use Goehr's idea of the work-concept to argue that there can be different work-concepts for different forms of music even within the same genre, which are related to their social, technological, and cultural context. Using Gell's ideas on the interrelations of corpuses of work as well as his ideas of the social impact of technical facility, I contrast the collaborative social environments, video work-concepts, and aesthetic expectations at play against the "standard view" of jazz. I show that due to the affordances of social media platforms, the ontologies of these practices combine elements of film, live music, and recorded music ontologies, and argue that the impact of new online reception environments on changing aesthetic ideals and work-concepts must be accounted for in future ontological discourse.

\section{Introduction}

It is a familiar sight on YouTube: a musician, multiplied across frames, harmonising with themself. Apps such as Acapella and other free video editing software make these self-collaborations possible, especially for professional musicians and social media contributors who have experience with musical composing and video editing. One of the most famous purveyors of this style of self-harmonisation is the jazz musician and composer Jacob Collier. These split-screen videos, however, can go beyond the original musician and offer frames for collaboration, as in the case of Collier's \#IHarmU series. 1 The \#IHarmU series see Collier surround and augment videos of his fans, treating them as collaborators. And yet, the project is still about Collier himself, as acknowledged by his fan commenters, who, while occasionally noting the musical skill of the featured fans, generally focus on idolising Collier. $\underline{2}$ The formal simplicity of the musical video belies the multitude of social, musical and visual intersections assembled within and around the practice of \#IHarmU, which is emblematic of the many entirely new forms of online audiovisual collaboration in jazz music. $\underline{3}$ 


\section{Visit the web version of this article to view interactive content.}

Video 1. Jacob Collier, "Jacob Collier's \#IHarmU Vol. 1," May 31, 2016, accessed May 7, 2020, https://www.youtube.com/watch? v=SM2nhLSeJX́g.

The socially dynamic collaboration of Collier's \#IHarmUs, along with other new audiovisual practices on social media, complicate traditional ontologies of recordings, jazz and audiovisual media. The new reception environments of social media afford different social engagement structures and formal possibilities for the practices these platforms host. These proliferating possibilities entail different ideas of what constitutes the focus of audience appreciation. The common name for this point of focus is the work, while the idea of what constitutes a work has been referred to by Lydia Goehr as the "work-concept." 4 Work-concepts have generally been explored in live and recorded reception environments, and are rarely discussed in terms of online communities. Jazz critics such as John Fisher note the "complexity of the jazz tradition" but do not begin to discuss online communities. $\underline{5}$ Collier's creations, and other novel parallel practices, are thus left under-theorised in much literature, thereby disregarding the influence of audiovisual content-focused social media platforms on artistic practice and existing genre ontologies. These new social media videos disrupt and blur the lines between live, recorded and audiovisual ontologies, as well as affecting the treatment of canons, causing the shifting of established aesthetics, and affording a change in social understandings of existing musical practices. These different forms and novel online reception environments are involved in the production of the changing work-concepts. But what are the work-concepts, and how do they differ from existing concepts of jazz, recordings, and audiovisual media? And how exactly do audiovisual practices on social media construct these concepts?

In order to answer these questions, I will investigate the ontology of examples of un-theorised audiovisual jazz practices on social media. There are two cases laid out below: fan-creator video collaboration, as exemplified by Jacob Collier's \#IHarmU project; and pedagogical transcription videos, shared to the Facebook page "Jam of the Week." When considered with the support of perspectives from performance musicology and art anthropology, the formats, aesthetic ideals and social context of the new audiovisual practices show the changes in work-concept afforded by the new reception environments and representational technologies of social media. The examples relate to various wellexplored ontologies including jazz's "standard view" and audiovisual media's film ontology. $\cdot$ Yet, through the example communities' divergence from these ontologies, the two case studies complicate critics' placid presentations of 'standard views' of jazz, as discussed by Fisher and Julian Dodd, audiovisual media, as discussed by André Bazin, Roger Scruton, and Ben Winters, and work ontology in general, as discussed by Goehr. ${ }^{?}$ 


\section{Work-Concepts of Art}

Work is a broad term. In the context of general artistic practice, it can be applied to anything considered art or artistic, used evaluatively to single out significance within particular Western practices, used to identify the artefact or concept central to aesthetic discussion within a field, or any combination of the three. Much of the discussion around its application has focused on what the properties of works are and whether it is a generic or a specific term. I interpret work as a generic term, and will use philosopher Andrew Kania's initial definition of a work as a "primary focus of appreciation" in a given artistic tradition, along with John Fisher's corollary that there may be more than one focus or work in each. $\underline{8}$ Using Kania's definition, works can be videos, music, visual art, or any number of other categories, thereby enabling musical videos such as Collier's to be perceived as works.

The "work-concept" mentioned above was originally coined by Lydia Goehr as the idea that music consists of works, and includes a variety of attendant socio-cultural baggage. 9 For Goehr, the workconcept exists as an "open" ontology rooted in social practices, which "projects" future performances while "regulat[ing]" what they might be. $\underline{10}$ Goehr's specific work-concept does not apply to all other musicking or creative practice; however, the historical and social rootedness of ontologies is universal. There are different work-concepts for different art forms, each of which relates to their social, technological, and cultural contexts. Therefore, as social media platforms bring new possibilities for social organisation, they afford new and changed ideas of the work. Given its focus on instantiation and liveness, two issues pertinent to works presented online, Goehr's work-concept is useful both as a term to understand the contextual individuality of work ontologies, while also in its specific case being a useful point of comparison to other ontologies.

\section{Pertinent Ontologies}

There are no investigations into the ontology of web content specific enough to provide a framework for this study. Additionally, there is insufficient exploration into jazz or film which directly discusses online ontology, and the impact of social media platforms on the content they bear is also not widely explored. Critics such as Jean Burgess and Joshua Greene engage with the impact of YouTube on its diverse content and consider aesthetic changes as well as the practical implications of a new reception environment. $\underline{11}$ Carol Vernallis has discussed various aesthetic changes in and caused by online media, while others, such as Jordan Schonig, have discussed aesthetic or formal trends on particular 
platforms. $\underline{12}$ However, across film, media and jazz scholarship, the ontological impact of social media is inadequately explored. As such, the discussion below is necessarily limited to audiovisual, jazz, performance, and art ontologies, with internet theory providing additional support.

Directly representational visual media such as film and sound recordings present an issue for art ontology as, through the fidelity of their representation, they appear to be presentations of reality, unmediated by artistic intention. Film critics such as Roger Scruton have historically held that photorealistic films are merely presentations of drama, due to the presentational, objective nature of photography. $\underline{13}$ André Bazin, meanwhile, has argued that photography itself is a direct presentation of the real world, lacking any kind of artistic interpretation; a picture is merely a "transference of reality," rather than a representation. $\underline{14}$ This is not a perspective all film critics share. Ben Winters, for example, argues that rather than film's appearance of fidelity leading to a direct presentation of reality, it instead suggests an aesthetic ideal of verisimilitude. $\underline{15}$ Actual objectivity and the aesthetic of objectivity are two distinct positions, and, further, some critics such as Rafe McGregor do not side with the objective view. $\underline{16}$ However, as Roland Barthes has noted, objectivity is an important association within the "code of connotation" of recording technology, and, therefore, the aesthetic of objectivity remains alive and well. $\underline{17}$

A crucial ontology for the aural element of the discussion of audiovisual media is the idea of the "standard view" of jazz, the central accepted ontology of the genre as defined by Dodd. $\underline{18}$ James Young and Carl Matheson argue after Dodd that standards are the jazz analogue for classical music's

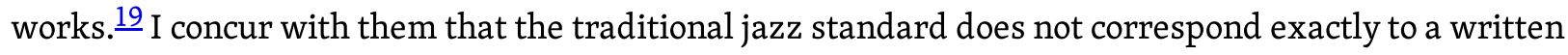
score, a chord sequence and melody, or any other specifiable set of conditions: it is an open concept. Kania expands on this, claiming that "jazz is not a work-performance tradition," as the type of "jazz works" is too open to feasibly be coherent. $\underline{20}$ However, Kania's claim is inconsistent with the experiences of jazz musicians and audiences, who, as Julian Dodd points out, would clearly agree that jazz standards do exist. $\underline{21}$ The prevailing standard view thus accepts standards as the primary work of jazz, a Margolisian type instantiated in token-performances. $\underline{22}$

\section{Collaboration and Distribution}

The examples I will explore have another element of subjectivity, in that they are comprised of musical performances and performers. Critics such as John Rink, Mine Dogantan-Dack and Emily Payne explore how the Western art music composer- and score-focused work-concept is stretched on 
its converse side by performers. $\underline{23}$ Their studies of classical performance show that works are musically defined beyond the compositional moment as musicians understand and redefine the work through (re)interpretation. Carolyn Abbate's concept of the "drastic" further highlights the power of performance as taking ownership of the music itself. $\frac{24}{2}$ She argues that performance has the power to override "gnostic," or knowledge-based, ideas of music, redefining music as something that is experienced, rather than understood. $\underline{25}$ Through using social media as a platform for their performances, amateur interpreters and collaborators can use these strategies to equal composers as remediators of musical meaning and value.

Anthropological strategies are useful to understand how these and other horizontal practices can construct works online. Ideas of the cultural distribution of works as explored by Georgina Born connects social interactions to the intertextual influences which exist between works on social media. $\frac{26}{2}$ For Born, works are made up of "social relations" which change what the work is over time, while works reflexively influence these same relations. $\underline{27}$ To Alfred Gell, works are not limited at their physical boundaries, as a corpus (a group of related works) is a single "distributed object." $\underline{28}$ This intertextual gestalt socially foreshadows and refers to itself as well as impacting on its viewers and creator(s). $\underline{\underline{29}}$ This extends Goehr's idea of a projective, regulative work: in Gell's view, multiple works are interlinked in a network of social influence, being changed by other works and interpretations, as well as having an impact on future creation and appreciation. I will use this distributed object ontology to account for the distributional and derivative practices afforded by social media.

Gell's anthropology also gives an insight into the mechanisms of social impact behind audiovisual works on social media. Due to social media's affordances for knowledge communities, works shared there often entail an "amateur aesthetic" whereby creators are revered for their skills by a community of fans of a particular practice, as discussed by Stephen Groening. $\cdot \underline{30}$ Gell's argument that technical facility mediates social influence is relevant to both the "soloist's art" of jazz, as termed by Frederick Garber, and to works which rely on social media platforms, due to their shared idealisation of virtuosity. $\frac{31}{}$ Gell argues that objects are extensions of people and, as embodiments of technical facility, works of art function by aesthetically "enchanting" viewers to affect their perceptions of others. $\underline{32}$ Upon perceiving a work, the viewer is struck by their inability to reproduce its technical facility, thereby socially elevating the owners and patrons of the work, who are perceived to possess the virtuosity the work embodies. I concur with Ross Bowden's illuminating critique of Gell, identifying technical virtuosity as not a sufficient or universal criterion for a work of art to be aesthetically valued..$\underline{33}$ Bowden gives the examples of "conceptual originality and ... [the capacity to] reveal in new and penetrating ways some aspect of the world" as two different aesthetic criteria which are paramount in Western visual art aesthetics. $\frac{34}{}$ However, Bowden's examples suggest to me a modified form of Gell's thesis, where virtuosity supersedes technical skill. Conceptual virtuosity (or the ability to 
manipulate ideas) and perceptive virtuosity account for Bowden's aesthetic ideals. Each aesthetic criterion can be matched to a corresponding axis of virtuosity, which identifies the work's level of engagement with that aesthetic ideal. Gell's idea of virtuosity as affording social impact can accurately account for modern aesthetics, such as the amateur aesthetic, by considering the axes of virtuosity which works engage with as a means to identify both the aesthetic ideals involved and the work's approach to them.

\section{Case Study: Jacob Collier's \#IHarmU}

Collier collaborates with his supporters to create \#IHarmUs: micro audiovisual compositions, which are typically 10 to 25 seconds in length. These videos are created by a supporter privately submitting a video of themself singing and/or playing an original passage, to which Collier subsequently provides further vocal and/or instrumental layers. Collier then overlays these backing vocals and/or instrumentals onto the submitted audio, imposing split-screen videos of himself playing or singing each layer around with the fan's video. The collaborations are ordered and posted as a set of around twenty to YouTube, with each fan-original preceding its collaboration (see Figure 1).

Collier's \#IHarmU is representative of a type of online music video which became popular in the 2010s, wherein split-screen video editing is used to present an artist playing multiple instruments at once. This type of video presentation will hereafter be referred to as $\mathrm{S}^{3} \mathrm{Vs}$ (Self Split-Screen Videos), and the following analysis of Collier's \#IHarmU stands for the ontology of $\mathrm{S}^{3} \mathrm{Vs}$ in general. 


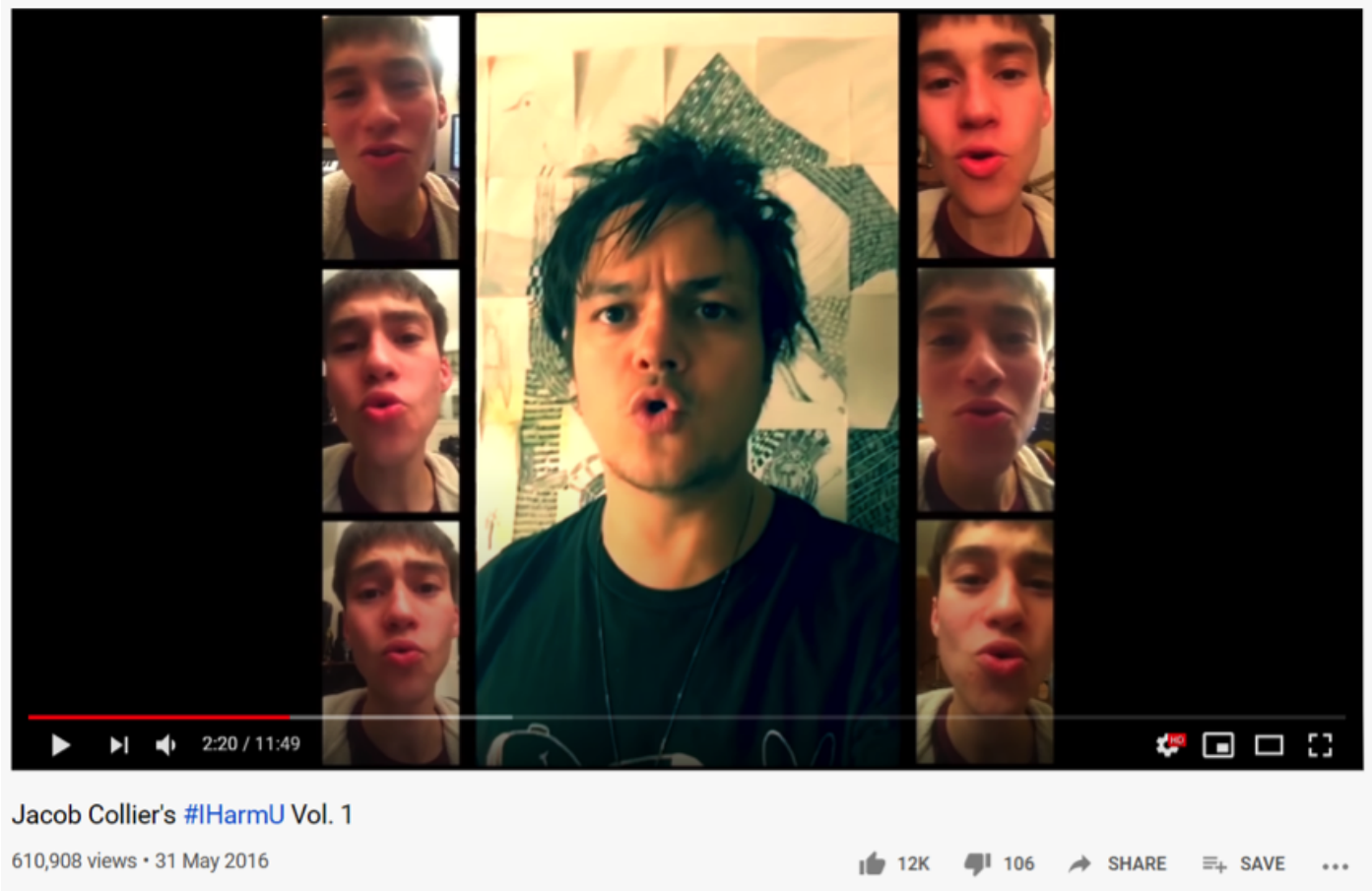

Figure 1. Screenshot taken from Jacob Collier, "Jacob Collier's \#IHarmU Vol. 1," May 31, 2016, accessed May 14, 2020, https://www. youtube.com/watch?v=SM2nhLSeJXg.

Collier's \#IHarmUs do not fit within any existing ontology of music. Like initial recordings of standards, \#IHarmUs are technically repeatable in that they could be reproduced by other musicians. However, they have not become involved in a canon of performances and, for this reason, they also do not align with the "standard view" vocal model. As well as not being performatively involved, Collier's collaborations are also exceptionally short. In the first \#IHarmU, each individual collaboration averages at around 18 seconds long. $\underline{35}$ There is no head re-statement and no repeated chord sequence, both of which are identifying (but not necessary) elements of the open concept of 'standard.' Collier's \#IHarmU videos do not fit within the standard view of jazz; however, as Fisher and Dodd argue, when something receives serious critical and social appreciation, one should regard it as a work until one finds evidence otherwise. $\underline{\underline{36}}$

The closest music philosophers have otherwise come to discussing online audiovisual jazz is considering the ontological status of recordings. I distinguish here between recordings and scores, where the former are perceived as coming after a performance, while the latter act as directions or instructions, coming before a performance. Jazz critics such as Kania often dismiss the ability of recordings to be significant works, a perception that is attached to ideas of their objectivity; for example, Kania comes to the conclusion that jazz records aim to transparently present a live performance situation. $\frac{37}{}$ Kania is right that there is a distinction to be made between recordings which 
are presented as recordings of live performances, and those which are not. Furthermore, he is accurate in his perception that standard view jazz performances, with exceptions, idealise liveness. Nevertheless, a significant proportion of audiovisual jazz on social media reflects a non-live, studio ideal.

This highlights the issues within the relationship of \#IHarmU to the standard view. There is a significant opposition between classical and jazz ontologies, and those of primarily audiovisual musics on the definition of the work. Current Western art music and standard view work-concepts agree that works are open, projective and regulatory, as stated above. Both classical and standard view jazz works are not fully bounded by a particular performance or artefact, while future and past performances impact on one another. Studio audiovisual works do not transcendentally unite multiple performances, but do so literally in an asynchronous compiled work. Recordings can be projective and regulatory of performances, as the music on the recording is sometimes interpreted by others, pedagogically or in performance. $\underline{38}$ They are also are open in the same sense as Western art music scores: if there can be a transcendent, unitary work in Western art music which is reified in the score, the same can be true for recordings. But the requirement which Goehr identifies for a work to be projective of inter-influential performances of itself is the product of a live music ontology. This is evident in film discourse, where, as Rafe McGregor and Noël Carroll affirm, the work-concept does not necessitate a canon of performances of a single work influencing each other. $\underline{39}$ Films are a form of motion picture, where projection is only required in a literal sense. Although McGregor's ontology is ocular-centric, it suffices in the current situation to support the assertion that films are not performed and are rarely re-interpreted by those who project or present them in the same means as classical or jazz music. This leads to films being considered works in their singularity; the impact of one film on another is not a product of a work-performance concept, but of intertextual stylistic influence. Musical videos native to social media often accord closely with this film work-concept, (re)producing intertextual influences rather than necessitating future performances of the same entire work, as Nicholas Cook notes in his gloss of Lawrence Lessig's concept of "Read/Write culture." $\underline{40}$

A more apt comparison for the \#IHarmUs is found in the film ontology interpretation of Margolis' type-token distinction, as laid out by Carroll and McGregor. $\underline{41}$ Social media-based audiovisual recordings like Collier's are distinct from films in their access practices, multiplied into tokens via digital reproduction, rather than through printing and projection. Like digital films, each work's (proto)type exists as a data stream on a hard drive. This data stream is where copyright and other legal rights derive from, similarly to autograph scores or original wax cylinders. Much like the autograph (through copying and performance) and the cylinder (through pressing and broadcasting), this data stream is multiplied into tokens or instances, fulfilling a key criterion of Goehr's work-concept framework. $\underline{42}$ Upon being uploaded to YouTube, the record is hosted in Google's cloud storage across 
various global servers. Through its access, the work is instanced further, projected through the infrastructure of the internet from servers and through routers into home computers, laptops, tablets, and phones around the world. A token data stream of the work is created and briefly possessed by those who view it in RAM and flash memory. The digitally accessed video is this mutable corpus of fragile instances, instanced freely at the moment of access, complicating Margolis's type-token distinction. This is true for any such video and is a significant element of the ontology of digital media.

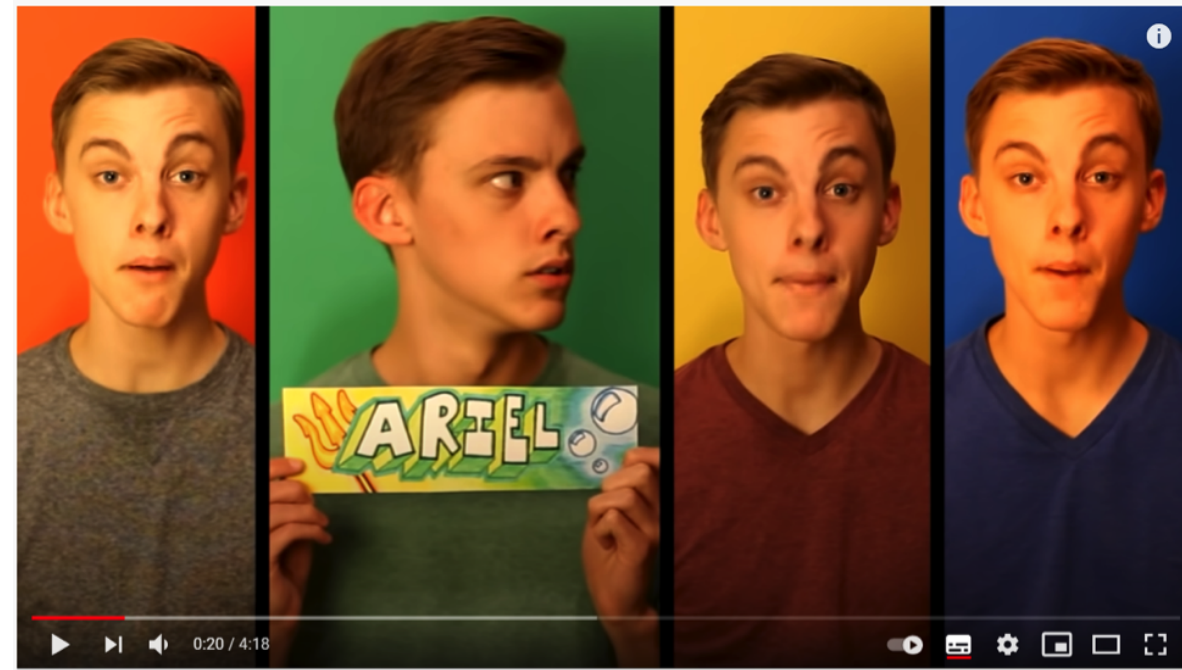

After Ever After - DISNEY Parody $91,673,776$ views $\cdot 13$ Mar 2013

If $1.9 \mathrm{M}$ I $28 \mathrm{~K} \rightarrow$ SHARE $\equiv+$ SAVE $\ldots$

Figure 2. Screenshot from Paint, "After Ever After - DISNEY Parody," March 13, 2013, accessed January 12, 2021, https://youtu.be/diU70Kshcj $\underline{A}$ ?t=20

When considering the \#IHarmUs as digital audiovisual works, the aesthetic ideals of their ontology differ from the audiovisual objectivity desired by Philip Alperson and André Bazin. $\underline{43}$ Collier's videos, and by extension all $\mathrm{S}^{3} \mathrm{Vs}$, play up the constructedness of audiovisual materials, and, as such, crack the glass of Alperson and Bazin's desired objectivity. The musician is shown playing at least two things at once, foregrounding the non-live, non-objective nature of the video. In most examples of the form, the musician wears different outfits in each split-screen frame, highlighting the temporal absurdity of simultaneously playing multiple parts of a song. For example, in Paint's famous a capella Disney parody, each T-shirt matches the colour themes of each princess whose story he sings (see Figure 2). The absurdity is also highlighted by the split-screen, which creates multiple frames. Film theory often deals with the frame as perceived as invisible to audiences, as part of the argued objectivity of photography, thereby providing the limit to Bazin's "transference of reality." $\underline{4}$ However, through the $S^{3} V$ 's split screen, multiple "realities" are presented simultaneously. This experience is not jarring for audiences, merely foregrounding the use of editing software as part of the amateur aesthetic which Groening identifies. $\underline{45}$ At the core of the $\mathrm{S}^{3} \mathrm{~V}$ work-concept, editing and camerawork are not used to 
present an objective view, in a transformation of the previous aesthetic ideal of objectivity in audiovisual media.

The amateur aesthetic on social media also incurs various expectations of virtuosity in audiovisual works. $S^{3} \mathrm{~V}$ works can be analysed to explore this virtuosity as affording their critical appreciation and

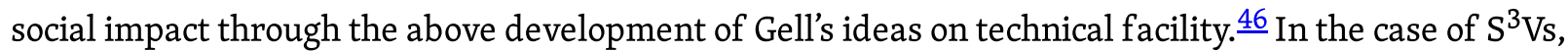
the axes of potential virtuosity are fourfold: musical virtuosity through self-collaboration on various instruments; video editing virtuosity; an increased focus on compositional skill (as all $\mathrm{S}^{3} \mathrm{Vs}$ are nominally self-arranged); and an increased emphasis on intertextual virtuosity. $\underline{47}$ These four axes of aesthetic attention each rest on the work-concept afforded by social media technologies, and represent a change from the previously established audiovisual and jazz work-concepts. For Collier, the video sharing website YouTube and crowdfunding website Patreon are the primary reception contexts which mediate the work. The submissions for Collier's \#IHarmU come from his Patreon supporters, members of the public who pledge monthly financial contributions to support his music-making. These supporters receive benefits such as attending virtual meetings with Collier and hearing demos of upcoming tracks. However, the \#IHarmUs and other compositions are available to watch on YouTube for free. The larger, non-paying YouTube audience is crucial to the style of the work, encouraging Collier's humorous and heartfelt approach. The virtuosic musicianship, composition and editing impresses an amateur (in Groening's sense of "loving") audience, driving their engagement through comments or likes, which leads to further viewers (and potential patrons) reaching the video. $\underline{48}$

Furthermore, in putting his supporters literally at the centre of his videos, Collier aims to repay the debt that social media celebrities are perceived to owe the fans who facilitate the star's rise to fame, while entrenching his social position through his superlative virtuosity. Collier's works use social media to enable one-to-one collaboration with his fans. Through the \#IHarmU project, Collier gives his Patreon supporters access to his musical skill, reciprocally promoting the musicking and social status of those who support him. Yet \#IHarmU is a tangled social nexus, as Collier is critically elevated for the complexity and virtuosity of his accompaniment. Though the fan submissions are nominally the lead part, Collier's accompaniment is the focus of each micro composition. Appreciation for the fan submissions is evident in the comments on Collier's videos, such as one left by "Michael," who wrote that "[the] Man that sang don't you worry child had some unreal control." $\underline{9}$ Collier's virtuosity, however, is clearly more valued, as seen in comments from in "Fagner Sousa," who writes "How many instrument [sic] do you play? / Jacob: Yes!" $\underline{50}$ The work relies on the collaboration between Collier and the fan, but is structured to highlight Collier's virtuosity. Collier surrounds the fan both visually and aurally, and has control over the method and the final edit. YouTube's social context encourages the amateur aesthetic and idea of the humble creative, while the platform's structure affords the uneven 
power dynamics through which these personae can be sustained. Through the organisation of virtual space, the platform mediates Goehr's work-concept ideal, of the unattainable authority of the creator, dividing videos from their comments sections just as audiences in auditoriums are divided from the stage. .51 The aesthetic and formal opportunities evident in \#IHarmUs and other $\mathrm{S}^{3} \mathrm{Vs}$ are reliant on YouTube's virtual architecture and social affordances, and thus the social media platform enables the $S^{3} V$ 's fascinating fusion of existing audiovisual and collaborative performance work-concepts.

\section{Case Study: Transcription Videos on "Jam of the Week"}

On the Facebook group "Jam of the Week," users are encouraged to post videos of themselves playing a solo over a standard relating to a composer, tune, or style specified by the admin that week. In comparison to YouTube videos, Facebook groups enable a relatively horizontal social reception environment by presenting everything posted to the group by any user and allowing other users to

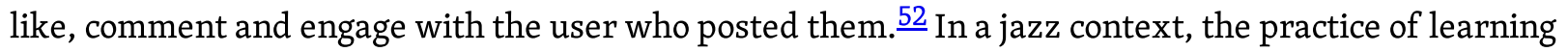
solos from famous recordings is known as transcription. Transcription does not necessarily include or refer to the creation of a score. Some weeks on "Jam of the Week" (JotW) are "transcription weeks," where users are encouraged to post transcriptions of recordings from that week's category. The group's feed thus consists of a combination of videos of original and transcribed solos performed by both individual professional and amateur musicians, along with positive and critical comments from various users.

Transcription is not a highly theorised practice in jazz ontology. Young and Matheson note that solos from "classic performances" are often transcribed (and sometimes turned into scores) as part of the pedagogical process, resulting in scores of originally score-less works. $\underline{53}$ However, according to the authors, these scores are "incomplete" in terms of giving an account of jazz works, as although the work within the standard view is the standard, it is not bounded by a score. $\underline{54}$ Fisher, meanwhile, has identified the processes of transcription and interpretation as sometimes part of the creation of works, noting that Lennie Tristano's treatment of "All of Me" has become a work in itself, "Line Up," due to being transcribed and performed by other musicians. $\underline{55}$ 


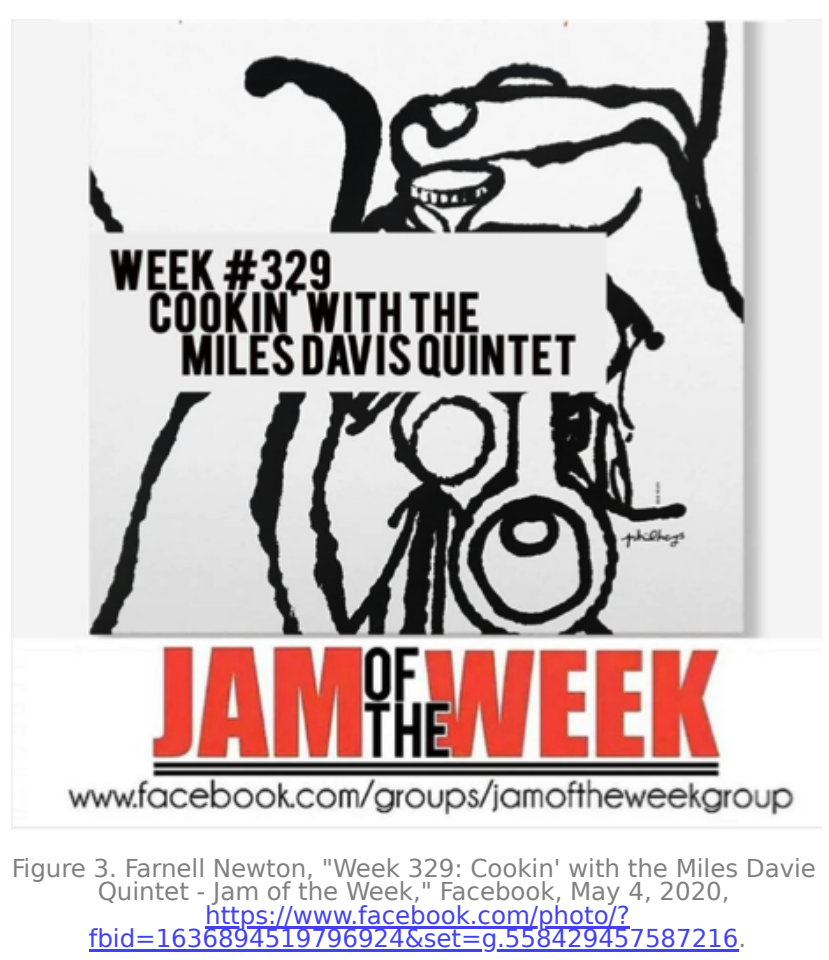

"Line Up" is a useful starting point for a study of transcriptions through Fisher's focus on the differences in "norms of compliance" between jazz and Western art music. $\underline{56}$ Norms of compliance also differ between the jazz practices of transcription and standard view jazz performance. In the standard view, performance necessitates liveness and individual expression, while transcription is more akin to Western art music in its ontology, as it entails an ideal of accuracy to a pre-existing work. This ideal of accuracy raises the issue of token-hood, as the ideal of accuracy to a pre-existing form suggests a type-token relationship. Transcriptions might be perceived as tokens of the type of the recording, as the record is the source of artistic intention, rather than the transcription. However, as established, live music ontologies require the type to be a locus of critical attention, accessed through token performances. Traditional transcription practices are personal and ephemeral, and do not meet these established standards. However, on JotW, transcriptions take the form of publically displayed audiovisual recordings.

Some critics, such as Alperson, would argue that these recordings cannot be works, as music's critical value lies in live performance. $\frac{57}{}$ Alperson's idea of objectivity is similar to that of Scruton and Bazin's similar senses with regard to film and photography. The similarity of Alperson's argument to that of Scruton and Bazin's ideas of photographic objectivity clarifies his belief that, just as in photographic and film objectivism, there is no potential or intent for expression in audio recording practices. But all varieties of recording involve choices, whether photographic, aural or audiovisual, even those which appear to be merely presentations of reality. Following Barthes, recordings, just like all media, contain some combination of denoted and connoted meaning, and the choices made by the 
creator(s) define and refine both the denoted and connoted content of the artefact. $\underline{58}$ Videos such as those on the JotW page are therefore representational and intentional, and can have critical value in themselves.

Audiovisual social media thus affords the elevation of transcription practices and their norms of compliance towards becoming works through the semi-permanence and social reception environment of publicly posting recordings. Through the Facebook community of musicians on JotW, transcriptions receive critical appreciation from users, which, following Kania's initial definition, identifies them as potential works. JotW states its purpose as a pedagogical space to "learn some new licks, network with fellow musicians and to promote the simple fact that we are all learning and striving to be better." 59 Despite allegedly being a place to receive criticism for the purpose of musical selfimprovement, comments swing to the adulatory and critical commentary becomes critical appreciation. A prime example of this is Josh Meader's transcription of David Binney's solo on "Aliso." In this case, among the 218 positive comments is Rohan Raj, who asks in humorous 18 th-century parlance "to be introduced to you as one of your greatest admirers," and states his desire "to have the fortune of watching your transcription of Cory Henry's solo from the [Snarky Puppy] song 'Lingus'." 60 Jazz transcription is often an isolated, personal practice. However, JotW's mediation of transcription creates a horizontal social reception environment where none existed, allowing for critical attention to be given to practitioners of transcription from their peers. Subsequently, through its recording and sharing, each audiovisual transcription becomes a semi-permanent micro-work, gleaning social attention through Facebook's affordances of community groups and video sharing.

The concepts of the distributed object and axes of virtuosity establish the social impacts of transcription practices beyond JotW. In a vindication of Gell's idea of artistic protension and retention, video transcriptions, scores and other artefacts and practices related to transcription distil jazz's social and stylistic web of historical influences, while recursively influencing its future performances. Elements retained through transcription from iconic solos become part of an instinctive repertory of motifs, techniques and approaches to improvisation which will be reproduced throughout a musician's lifetime, the transcription providing for future performances of solos over standards. Transcription is thus oriented towards the standard view while situated outside it, due to the juxtaposed ideals of accuracy and individuality. Transcribed solos are rarely played onstage; rather, they are generally understood simply as displays of virtuosic skill. It is this virtuosic skill that Gell claims creates our fascination with art. $\underline{61}$ Without a reception environment, transcription does not mediate social relations, existing merely as a process which forms a nexus of personal style and influence. But as social acts of retention, JotW's transcription videos valorise the recordings they are drawn from. As seen above, transcriptions can become work-like, excerpts becoming part of a corpus of appreciated performances, while also engaging in the social-status process of canonising the works. To identify a solo on hearing it gives the listener access to a degree of its social status, with knowledge passing as 
ownership. But to transcribe it is to re-produce the technical virtuosity of the original, which elevates both the solo and the transcriber. In the above example, through taking ownership of the virtuosity of Binney's solo, Meader also comes to possess Binney's status. Through the affordances of Facebook, transcription becomes a site of complex social mediation, while in its videoed virtuosity it makes explicit the mechanism of propagation for jazz's ideal of stylistic imitation.

Jazz transcription can be perceived either as works, or as a work-adjacent practice. Transcription videos do not stand alone in the sense that works are identified to do so, as a referential reproduction of another performance, but neither does any type which is instantiated in multiple tokens. Famous performances and solos already exert some influence on future performances of a work, as accepted by Fisher and highlighted in Goehr's idea that works are "emergent." $\underline{62}$ But in this case, works and styles are also affected by their pedagogical context, which can solidify or erode the improvisatory possibilities of the work, through the valorisation and canonisation of solos and styles. Transcription videos of famous solos by amateur musicians engage in the experiential, performer-focused redefinition of the understanding of works as laid out by Western art music critics. .63 Social media enables this access to re-definitional authority through its communities of critical attention, permitting broad access to drastic experiences which had been generally restricted to promoters and venues, and through its new affordances of audiovisual virtuosity and the amateur aesthetic, allowing amateurs to be indistinguishable from professionals (in the sense of those working in the established music industry). The work-concepts engendered by social media communities are likely not fairer in their promotional practices, merely changing the gatekeeper. But the hyper-individuation afforded by platform algorithms combined with the amateur aesthetic enables the horizontal transformation of the standard view, where performers are placed alongside composers at the heart of the practice.

However, the widespread practice of transcription from recordings on JotW and elsewhere makes it clear that the standard view is not the only ontology of jazz standards. There are at least two parallel jazz work-concepts within this jazz community, including the standard view and the record-as-work, with the latter valued pedagogically and the former valued in live performance. In the context of transcription, the standard exists as the established open concept related to chords, style, tune and meter, while the recording is a rigidly defined artefact which entails a highly accurate reproduction. Clearly, even within standard view jazz, there is no single work-concept, and the practice of videotranscription on JotW highlights this duality through further complicating it. In contrast to the hierarchical reception environment of Collier's composer- and arranger-focused collaborations, the practice of video transcription as seen on JotW engages in a social, collaborative process of work- and style-definition. Through its reproduction in the audiovisual music presented on the Facebook group, transcription subverts the ideals of solo-focused standard form and affords a critical focus on records and solos as critically appreciable, instantiable works in themselves. 


\section{Conclusion}

Dodd's standard view of jazz cannot account for audiovisual jazz works and practices shared on social media, and neither can existing audiovisual ontologies. These distinct platforms afford many different ideals, aesthetics, reception environments and presentation formats to the communities and creators that use them. Ontologies such as the record-as-work and the standard view are complicated by the addition of various visual-based axes of virtuosity, which juxtaposes them with existing audiovisual work-concepts. Social platforms open new potentials for reception environments and financial models, as seen in Collier's $\mathrm{S}^{3} \mathrm{Vs}$. Video transcription practices such as those seen on JotW have transformed existing ontological boundaries, shifting aesthetic ideals and focal points of critical attention. As Goehr explains, work-concepts govern not only the way that music can be played but extend far beyond the stage. $\frac{64}{}$ Online platforms and their virtual spaces provide new equivalents for auditoriums, gig venues, practice rooms, and other not-yet-understood places, affording new work-concepts in much the same way as Goehr describes the impact of the concert hall, and we must account for the effects of these reception environments on existing audiovisual and jazz ontologies. Understanding musical videos on social media requires the fusion of old and new approaches to ontology and the work, and an intimate social and technical knowledge of the communities and formats involved. New scholarship is necessary to move beyond the standard view.

This essay only scratches the surface of under-theorised work-concepts in jazz. Though Fisher does not contribute to rectifying the problem, he is correct to note that fusion, Latin, free jazz and many other jazz genres have yet to have their ontologies considered, and there is a need for further study to rectify this deficit. $\underline{65}$ Furthermore, critics have not significantly covered any other philosophical alternatives as a challenge to the idea of the musical work in the context of jazz. For example, in the context of online platforms, the ontology of the term 'content' is a font of further research. Ontologies of cultural objects are shifting, unstable social agreements, reliant on language, and mediated and transformed by discursive work. The academic study of ontology, including this essay, takes part in their construction. The work-concept is agreed (or not) between those involved in any way - fans, musicians, audiences, music companies, academics - who all collaborate in treating music in a particular way. To attempt to state anything definitive about ontologies is to claim that they are no longer being negotiated, that they have become static - and they are anything but. 


\section{Bibliography}

Abbate, Carolyn. "Music - Drastic or Gnostic?." Critical Inquiry 30, no. 3 (Spring 2004): 505-536.

Alperson, Philip. "On Musical Improvisation." The Journal of Aesthetics and Art Criticism 43, no.1 (Autumn 1984): 17-29.

Barthes, Roland. "The Photographic Message." In Image, Music, Text, edited by Stephen Heath, 15-31. London: Fontana Press, 1987.

Bazin, André. "The Ontology of the Photographic Image." Translated by Hugh Gray. Film Quarterly 13, no. 4 (Summer 1960): 4-9.

Bonini, Tiziano and Alessandro Gandini. "'First Week Is Editorial, Second Week Is Algorithmic': Platform Gatekeepers and the Platformization of Music Curation." Social Media + Society 5, no. 4 (November 2019): 1-11.

Born, Georgina. "On Musical Mediation: Ontology, Technology and Creativity." Twentieth-Century Music 2, no. 1 (March 2005): 7-36.

Bowden, Ross. "A Critique of Alfred Gell on Art and Agency." Oceania 74, no. 4 (June 2004): 309-324. https://doi.org/10.1002/j.1834-4461.2004.tb02857.x.

Burgess, Jean and Joshua Green. YouTube: Online Video and Participatory Culture. Cambridge: Polity Press, 2009.

Carroll, Noël. "Defining the Moving Image." In Philosophy of Film and Motion Pictures: An Anthology, edited by Noël Carroll and Jinhee Choi, 113-133. Oxford: Blackwell, 2006.

Cook, Nicholas. "Beyond Music: Mashup, Multimedia Mentality, and Intellectual Property." In The Oxford Handbook of New Audiovisual Aesthetics, edited by John Richardson, Claudia Gorbman and Carol Vernallis, 53-77. Oxford: Oxford University Press, 2013.

Dodd, Julian. "Upholding Standards: A Realist Ontology of Standard Form Jazz." The Journal of Aesthetics and Art Criticism 72, no. 3: 277-90.

Dogantan-Dack, Mine. "The Art of Research in Live Music Performance." Music Performance Research 5 (2012): 34-48. 
Fisher, John Andrew. "Jazz and Musical Works: Hypnotized by the Wrong Model." The Journal of Aesthetics and Art Criticism 76, no. 2 (Spring 2018): 151-62.

Frith, Simon. Performing Rites: On the Value of Popular Music. Cambridge, Mass: Harvard University Press, 1996.

Garber, Frederick. "Fabulating Jazz." In Representing Jazz, edited by Krin Gabbard, 70-103. Durham, North Carolina: Duke University Press, 1995.

Gell, Alfred. "The Technology of Enchantment and the Enchantment of Technology." In Anthropology, Art and Aesthetics, edited by Jeremy Coote and Anthony Shelton, 40-63. Oxford: Clarendon Press, 1994)

Gell, Alfred. Art and Agency: An Anthropological Theory. Oxford; New York: Clarendon Press, 1998.

Goehr, Lydia. The Imaginary Museum of Musical Works: An Essay in the Philosophy of Music, 2nd edition. Oxford; New York: Oxford University Press, 2007.

Groening, Stephen. "Introduction: The Aesthetics of Online Videos." Film Criticism 40, no. 2 (June 2016).

Jam of the Week. "About This Group." Accessed May 5, 2020.

https://www.facebook.com/groups/jamoftheweekgroup/about.

Jenkins, Henry. Convergence Culture: Where Old and New Media Collide. New York; London: New York University Press, 2006.

Kania, Andrew. "All Play and No Work: An Ontology of Jazz." The Journal of Aesthetics and Art Criticism 69, no. 4 (Autumn 2011): 391-403.

Lessig, Lawrence. Remix: Making Art and Commerce Thrive in the Hybrid Economy. New York: Penguin, 2009.

Margolis, Joseph. Art and Philosophy. Brighton: Harvester Press, 1980.

Massanari, Adrienne. "\#Gamergate and The Fappening: How Reddit's Algorithm, Governance, and Culture Support Toxic Technocultures." New Media \& Society 19, no. 3 (March 2019): 329-346.

McGregor, Rafe. "New/Old Ontology of Film." Film-Philosophy 17, no. 1 (2013): 265-80.

Newton, Farnell. "Week 329: Cookin' with the Miles Davies Quintet - Jam of the Week." Facebook, May 4, 2020, accessed February 14, 2021. https://www.facebook.com/photo/?

fbid $=1636894519796924 \&$ set $=g .558429457587216$. 
Payne, Emily. "Creativity Beyond Innovation: Musical Performance and Craft." Musicae Scientiae 20, no. 3 (September 2016): 325-344.

Rink, John. "Translating Musical Meaning: The Nineteenth-Century Performer as Narrator." In Rethinking Music, edited by Nicholas Cook and Mark Everist, 217-238. Oxford: Oxford University Press, 1999.

Schonig, Jordan. “Liking' as Creating: On Aesthetic Category Memes.” New Media \& Society 22, no. 1 (January 2020): 26-48.

Scruton, Roger. "Photography and Representation." Critical Inquiry 7, no. 3 (Spring 1981): 577-603.

Small, Christopher. Musicking: The Meanings of Performing and Listening. Middletown: Wesleyan University Press, 1998.

Vernallis, Carol. "Accelerated Aesthetics: A New Lexicon of Time, Space, and Rhythm." In The Oxford Handbook of Sound and Image in Digital Media, edited by Carol Vernallis, Amy Herzog and John Richardson, 707-731. Oxford: Oxford University Press, 2013.

Vernallis, Carol. Unruly Media: YouTube, Music Video, and the New Digital Cinema. Oxford: Oxford University Press, 2013.

WhatIs.com. "Instance." September 2008, Accessed May 14, 2020.

https://whatis.techtarget.com/definition/instance.

Winters, Ben. Music, Performance, and the Realities of Film: Shared Concert Experiences in Screen Fiction. New York: Routledge, 2014.

Young, James O., and Carl Matheson. "The Metaphysics of Jazz." The Journal of Aesthetics and Art Criticism 58, no. 2 (Spring 2000): 125-133.

\section{Media Cited}

Jacob Collier. "Jacob Collier's \#IHarmU Vol. 1." YouTube video, 11:49. May 31, 2016. Accessed May 7, 2020. https://www.youtube.com/watch?v=SM2nhLSeJX

Josh Meader. "My transcription of David Binney's godly solo on his tune Aliso." Facebook, April 21, 2020. https://www.facebook.com/groups/jamoftheweekgroup/permalink/2923939211036217/. 
Paint. "After Ever After - DISNEY Parody." YouTube video, 4:18. March 13, 2013. Accessed January 12, 2021. https://youtu.be/diU70Kshcj $\underline{\text { A?t=20. }}$

\section{Biography}

Chris Cottell is an academic and musician with interests in genre, social media, and the internet. His most recent work includes presenting the paper “'I Play The Lick for Five Hours Straight': The Life and Un-Death of a Jazz Meme" at Documenting Jazz 2020. He read for a BA in Music at the University of Oxford and is now completing an MA in Music at Goldsmiths, University of London. In the intervening years he worked as a librarian at Christ Church, and more recently in the Music section of the Bodleian Library. He writes academically on internet memes and internet music, composes, writes poetry, and plays drums, percussion, and piano.

\section{Footnotes}

1. \#IHarmU is both Collier's title and his social media hashtag for his series of fan-harmonisation videos. The combination of these two elements into one shows the active formal innovation of audiovisual works on social media. $\subseteq$

2. For examples of this admiration, see comments from Peter Panda and Urahara Mitchell on Jacob Collier, "Jacob Collier's \#IHarmU Vol. 1," May 31, 2016, accessed May 7, 2020, https://www.youtube.com/watch?v=SM2nhLSeJ㯊.

3.

Music videos are a genre of audiovisual work with a separate work-concept; the use throughout of the term 'musical video' aims to subsume any practices of musicking involved using video as their carrier format (the term musicking derives from Christopher Small, Musicking: The Meanings of Performing and Listening (Middletown: Wesleyan University Press, 1998));

The idea of a carrier format I take from Henry Jenkins, Convergence Culture: Where Old and New Media Collide (New York; London: New York University Press, 2006).

4. Lydia Goehr, The Imaginary Museum of Musical Works: An Essay in the Philosophy of Music, $2^{\text {nd }}$ edition (Oxford; New York: Oxford University Press, 2007), $4 . \subseteq$ 
5. John Andrew Fisher, "Jazz and Musical Works: Hypnotized by the Wrong Model," The Journal of Aesthetics and Art Criticism 76, no. 2 (Spring 2018): 157.

6.

Julian Dodd punningly coins the term "standard view," referring to the realist, socially accepted ontology where jazz standards are works.

Julian Dodd, "Upholding Standards: A Realist Ontology of Standard Form Jazz," The Journal of Aesthetics and Art Criticism 72, no. 3 (Summer 2014): 277.

7.

Fisher, "Jazz and Musical Works," 157;

Dodd, "Upholding Standards," 277-287;

André Bazin, "The Ontology of the Photographic Image," trans. Hugh Gray, Film Quarterly 13, no. 4 (Summer 1960): 4-9;

Roger Scruton, "Photography and Representation," Critical Inquiry 7, no. 3 (Spring 1981): 577-603;

Ben Winters, Music, Performance, and the Realities of Film: Shared Concert Experiences in Screen Fiction (New York: Routledge, 2014), 188-198;

Goehr, The Imaginary Museum of Musical Works, 1-9.

8.

Kania later refutes this definition, but I find it sufficient;

Andrew Kania, "All Play and No Work: An Ontology of Jazz," The Journal of Aesthetics and Art Criticism 69, no. 4 (Autumn 2011): 391.

Fisher, "Jazz and Musical Works," 154.

9. Goehr, The Imaginary Museum of Musical Works, $4 . \boxminus$

10. Ibid., 89-90.

11. Jean Burgess and Joshua Green, YouTube: Online Video and Participatory Culture (Cambridge: Polity Press, 2009), 1-37 for practical implications, 38-57 for some aesthetic effects. $\subseteq$ 12. 
Carol Vernallis, Unruly Media: YouTube, Music Video, and the New Digital Cinema (Oxford: Oxford University Press, 2013), 1-15;

Carol Vernallis, "Accelerated Aesthetics: A New Lexicon of Time, Space, and Rhythm," in The Oxford Handbook of Sound and Image in Digital Media, ed. Carol Vernallis, Amy Herzog and John Richardson (Oxford: Oxford University Press, 2013), 707-729 but specifically 709;

Jordan Schonig, “'Liking' as Creating: On Aesthetic Category Memes,” New Media E Society 22, no. 1 (January): 26-48, 7.ㄹ

13. Scruton, "Photography and Representation," 598-603.

14. Bazin, "The Ontology of the Photographic Image," $8 . \pm$

15. Winters, Music, Performance, and the Realities of Film, 188-198.

16. Rafe McGregor, "A New/Old Ontology of Film," Film-Philosophy 17, no. 1 (2013): 267-270.

17. Roland Barthes, "The Photographic Message," in Image, Music, Text, ed. Stephen Heath (London: Fontana Press, 1987), 28.

18. Dodd, "Upholding Standards," $1 . \Leftarrow$

19. James O. Young and Carl Matheson, "The Metaphysics of Jazz," The Journal of Aesthetics and Art Criticism 58, no. 2 (Spring 2000): 125-133. $\leftrightarrows$

20. Kania, "All Play and No Work," 400.

21. Dodd explains "the jazz cognoscenti treat standard form jazz as ontologically akin to classical music... People knowledgeable about jazz speak and act as if 'Straight, No Chaser' is a multiply performable entity." See Dodd, "Upholding Standards," 277.

22. Joseph Margolis's type-token dichotomy defines art objects as tokens, instantiating a particular cultural entity, the type. Types are definitive, while tokens reify types. Some objects are the sole token of their type, while other types are embodied in multiple tokens. See Joseph Margolis, Art and Philosophy (Brighton: Harvester Press, 1980), 20.

23. 
John Rink, "Translating Musical Meaning: The Nineteenth-Century Performer as Narrator," in Rethinking Music, ed. Nicholas Cook and Mark Everist (Oxford: Oxford University Press, 1999), 217238;

Mine Dogantan-Dack, "The Art of Research in Live Music Performance," Music Performance Research 5 (2012): 34-48;

Emily Payne, "Creativity Beyond Innovation: Musical Performance and Craft," Musicae Scientiae 20, no. 3 (September 2016): 325-344.

24. Carolyn Abbate, "Music - Drastic or Gnostic?," Critical Inquiry 30, no. 3 (Spring 2004): 505-509. $\doteq$ 25. Ibid., 505-536.

26. Georgina Born, "On Musical Mediation: Ontology, Technology and Creativity," Twentieth-Century Music 2, no. 1 (March 2005): 7-36.

27. Ibid., 7. $\subseteq$

28. Alfred Gell, Art and Agency: An Anthropological Theory (Oxford: New York: Clarendon Press, 1998), 220 as a gloss of one meanings of Marquesan "tiki," as in "portion"/"share"; 221-258 turning towards explore stylistic and social influence. $€$

29. Ibid., 221-242.

30.

The notion of 'knowledge communities' is discussed by Henry Jenkins, who discusses how the internet allows groups of consumers to mutually benefit from their relevant expertise. For more on this, see Jenkins, Convergence Culture, 33-82;

Stephen Groening details the amataeur aesthetic in "Introduction: The Aesthetics of Online Videos," Film Criticism 40, no. 2 (June 2016): paragraph 4-9. $\doteq$

31.

Alfred Gell, "The Technology of Enchantment and the Enchantment of Technology," in Anthropology, Art and Aesthetics, ed. Jeremy Coote and Anthony Shelton (Oxford: Clarendon Press, 1994), 46-47;

Gell, Art and Agency, 71-95;

Frederick Garber, "Fabulating Jazz," in Representing Jazz, ed. Krin Gabbard (Durham, North Carolina: Duke University Press, 1995), 70.

32. Gell, "The Technology of Enchantment," 1. 
33. Ross Bowden, "A Critique of Alfred Gell on Art and Agency," Oceania 74, no. 4 (June 2004): 320323.

34. Ibid., 323.

35. Not including the statement of the fan's recording on its own.

36.

This is regarded as the "realist" view: "an ontological theory of standard form jazz ... should cohere with the corresponding critical and appreciative practice." See Dodd, "Upholding Standards," 277;

Fisher agrees "since there are musical works in classical music, there are musical works in jazz unless there is a compelling reason to deny this." See Fisher, "Jazz and Musical Works," 152. 37. Kania, "All Play and No Work," 399-400.

38. Simon Frith, Performing Rites: On the Value of Popular Music (Cambridge, Mass: Harvard University Press, 1996), 54-55, 71-86.

39.

McGregor, "A New/Old Ontology of Film," 275-276;

Noël Carroll, "Defining the Moving Image," in Philosophy of Film and Motion Pictures: An Anthology, ed. Noël Carroll and Jinhee Choi (Oxford: Blackwell, 2006), 127-129.

40.

Nicholas Cook, "Beyond Music: Mashup, Multimedia Mentality, and Intellectual Property," in The Oxford Handbook of New Audiovisual Aesthetics, ed. John Richardson, Claudia Gorbman and Carol Vernallis (Oxford: Oxford University Press, 2013), 54-55;

Lawrence Lessig, Remix: Making Art and Commerce Thrive in the Hybrid Economy (New York: Penguin, 2009), 97. $\subseteq$

41.

Carroll outlines this interpretation, with the original cut as the type and the individual projection as the token, which McGregor further illustrates. Carroll, "Defining the Moving Image," 127-129;

McGregor, "A New/Old Ontology of Film," 275-276.

42. 'Instance' is a word taken from the Object Oriented Programming lexicon, which means a single occurrence of a common type of object. It unites both digital and the type-token metaphors. For 
more on this, see "Instance," WhatIs.com, accessed May 14, 2020, https://whatis.techtarget.com/definition/instance. $\doteq$

43.

Philip Alperson, "On Musical Improvisation," The Journal of Aesthetics and Art Criticism 43, no.1 (Autumn 1984): 26;

Bazin, "The Ontology of the Photographic Image," $8 . \subseteq$

44. Ibid., 8.

45. Groening, "Introduction," paragraph $4-9$.

46. Gell, Art and Agency, 71-95. $\subseteq$

47. This is the skill of recombination: a virtuosic manipulation of references and quotations. $\bullet$

48. Groening, "Introduction," $2 . \pm$

49. Michael, 2017, comment on, Collier, "\#IHarmU Vol. 1," https://www.youtube.com/watch? $\underline{\mathrm{v}=\mathrm{SM} 2 \mathrm{nhLSeJ}} \underline{\mathrm{X} g}$.

50. Fanger Sousa, 2019, comment on, Collier, "\#IHarmU Vol. 1," https://www.youtube.com/watch?

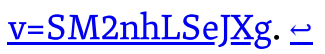

51. Goehr, The Imaginary Museum of Musical Works, 153-160.

52.

This does not account for the actions of Facebook's algorithm in presenting more liked or engaged with content. For more on algorithm studies, see Adrienne Massanari, "\#Gamergate and The Fappening: How Reddit's Algorithm, Governance, and Culture Support Toxic Technocultures," New Media \& Society 19, no. 3 (March 2019);

Tiziano Bonini and Alessandro Gandini, "'First Week Is Editorial, Second Week Is Algorithmic': Platform Gatekeepers and the Platformization of Music Curation," Social Media + Society 5, no. 4 (November 2019). $\leftrightarrows$

53. Young and Matheson, "The Metaphysics of Jazz," 125.

54. Ibid. $\triangleq$

55. Fisher, "Jazz and Musical Works," 157. 
56. Ibid. $\triangleq$

57. Alperson, “On Musical Improvisation," $26 . \leftrightarrows$

58. Barthes, "The Photographic Message," 17-20.

59. Jam of the Week, "About This Group," accessed May 14, 2020,

https://www.facebook.com/groups/jamoftheweekgroup/about..$\subseteq$

60. Rohan Raj, May 5, 2020, comment on Josh Meader, "My transcription of David Binney's godly solo on his tune Aliso," Facebook, April 21, 2020,

https://www.facebook.com/groups/jamoftheweekgroup/permalink/2923939211036217/.

61.

Gell, "The Technology of Enchantment," 46-47;

Gell, Art and Agency, 71-95.

62. Goehr, The Imaginary Museum of Musical Works, $89 . \pm$

63.

Rink, "Translating Musical Meaning," 217-238;

Dogantan-Dack, "The Art of Research," 34-48;

Payne, "Creativity Beyond Innovation," 325-344;

Abbate, "Music," 505-536.

64. Goehr, The Imaginary Museum of Musical Works, 235. $\subseteq$

65. Fisher, "Jazz and Musical Works", 157. $\subseteq$ 